\title{
Comparisons and Analysis on Architectural Features of Seven Typical Traditional Dwellings in China
}

\author{
Tang, Si-Yin* \\ Lee, Yeun-Sook**
}

\begin{abstract}
The ancestors of China created various proper dwellings in the vast Chinese lands, according to distinct geographical environment, climate, and special local products. The purpose of this study is to compare features of 7 typical traditional Chinese dwellings in different areas from historical, geographical, structural and tinctorial aspects, in order to see what the differences are and rearrange them by these 4 different scales as estimate standards. By Comparing features between 7 traditional dwellings, advantages and disadvantages of them were found out. Not only natural terrain but also cultural mentality is an important factor that effected on the changes of regionality. The result showed that historical length in a certain extent reflected the differences between dwellings in different areas; there are more regular type dwellings in the northern China; dwellings in different structural material types following their regions; and, southern dwellings prefer natural and simple exterior colors. Also From construction aesthetics and culture perspective, Different cultures have cultivated and brought out different dwelling styles. Thus, protecting on traditional dwellings is of great necessities and this study will bring benefits in many aspects. For a further research, the result of this study can be utilized as the base data that suggest directions for effective Chinese residence planning in different areas meeting different demands.
\end{abstract}

Keywords : comparison, traditional dwelling, architectural features, China

\section{Introduction}

\subsection{Background}

Chinese traditional architecture is a style of architecture that took shape thousands of years ago. Since the Tang Dynasty, Chinese traditional architecture has had a major influence on the architectural styles of Japan, Korea and Vietnam. Traditional dwelling, as a part of traditional architecture, is a culture tool that enables people to see through a certain generation, and the resident types in a specific cultural area that are both physical and spiritual results vividly formed by residents' life activities (Shan, 2003, pg.3, para.2, trans. by author). Therefore, traditional dwelling culture, as the essential area of human's life, is reflecting various meanings of the complicated environment. The forms and spacial varieties are the results of the interaction in human life.

The specialized study of Chinese traditional dwellings have become a hot academic topic home and abroad.

\footnotetext{
* Main author, Master of Interior Architecture \& Built Environment Dep. Yonsei University（dangsiin@gmail.com)

** Corresponding author, Professor of Interior Architecture \& Built Environment Dep.Yonsei University (Yeunsooklee@yonsei.ac.kr)
}

According to distinct geographical environment, climate and several special local products, Chinese ancestors have created various proper dwellings that are suitable for people to live in the vast Chinese land.

\subsection{Purpose and Necessity}

The purpose of this study is to compare features of 7 typical traditional Chinese dwellings in different areas from historical, geographical, structural and tinctorial aspects, in order to see what the differences are and rearrange them by these 4 different scales as estimate standards to find out both direct and indirect regulars among them. The necessity of carry out this study consists of two specific departs. Firstly, "nowadays the protection and development of Chinese traditional dwellings are in an aimless and careless situation during the urbanization process so that more and more traditional dwellings in different areas lost their primitive traditional features, and their premier usage for people's resident life has also been weakened"1). Most of them are remodeled to be café shops or guest houses mainly opened for tourists (Sha, 2000, pg.6, para.2, trans. by author). This

1) Weston, R. \& Blondal, J. I. (2002). Utzon : inspiration, vision, architecture. p.11. 
assumed a deep crisis of traditional culture decline.

Furthermore, different region has its different culture. China's vast land makes Chinese traditional dwelling in varied forms (Wang, 2006, pg.23, para.5, trans. by author). Even though there are lots of researches on traditional dwellings inland, such as analysis concerned on structure, category and distribution individually, few or none focused on concluding and comparing the features of dwellings placed at different areas. "According to international investigation, the Quadrangles in Beijing is generally known as a typical traditional dwelling of China, but other types that occupied quite a number of proportion are rarely concerned"2). So other traditional dwellings, with their typical attribution and unique features, should be presented to the world too.

\section{Literature Review}

\subsection{Classification of Traditional Chinese Dwelling}

Ancient Chinese architecture reflects the clear ritual thought and pays attention to social hierarchy. There are strict regulations on shape, color, size, structure, components and so on (Wang, 2002, pg.161, para.4, trans. by author).

Since ancient times, traditional dwellings had a wide range of forms that were classified by patriarchal ritual, folk customs, climate, geographical condition and other factors. There are over 40 vernacular dwelling types in China (Zhao, 2006, pg.11, para.1, trans. by author). It is not easy to cover all residential design types at this time. Therefore, it is necessary to classify them by a multi-angle residential classification.

\section{Classification based on shapes}

From the shape point of view, they are divided into regular type and irregular type. A large number of dwellings are in a regular structural shape that first demonstrated in the layout of the axial symmetry plane (Zhong, 2006, pg.37, para.2, trans. by author). Peking quadrangle is a typical regular traditional dwelling, it is strictly laid out on axis. That layout is in line with traditional Chinese patriarchal clan rules and feudal ethnics. The distribution of rooms is based on status and ages (Shan, 2003, pg.13, para.9, trans. by author). Irregular dwellings are more common in the Southern China. Especially in the hilly areas, because of the complex terrain geography, architectures had to follow the local conditions. Westwern Hunan dwelling Diaojiaolou is a typical

2) Schinz, A. (1996). The Magic Square: cities in ancient China, Edition AxelMenges, p.427. irregular traditional dwelling, it is built against mountains with free style and imagination, built with natural condition for avoiding of changing nature and environment. It is not strict on aspect or rules but focus on economy, functionality and practicability.

Table 1. Shape classification of traditional dwellings

\begin{tabular}{|c|c|c|}
\hline Shapes & $\begin{array}{l}\text { Typical } \\
\text { design }\end{array}$ & $\begin{array}{l}\text { Corresponding } \\
\text { dwellings }\end{array}$ \\
\hline Regular & $\begin{array}{l}\text { Courtyard } \\
\text { (square), } \\
\text { The Earth } \\
\text { Tower(round), } \\
\text { Mongolian } \\
\text { yurt(round) }\end{array}$ & $\begin{array}{l}\text { Peking quadrangle, } \\
\text { Anhui dwelling, } \\
\text { Shandong dwelling, } \\
\text { Shanxi dwelling, } \\
\text { Fujian dwelling, } \\
\text { Inner Mongolia dwelling }\end{array}$ \\
\hline Irregular & $\begin{array}{l}\text { Ganlan Wood } \\
\text { building, Cave-style } \\
\text { dwelling }\end{array}$ & $\begin{array}{l}\text { Western Hunan hanging house } \\
\text { (Diaojiaolou), } \\
\text { Yunnan bamboo house, Shanxi } \\
\text { cave house, } \\
\text { Henan cave house }\end{array}$ \\
\hline
\end{tabular}

Classification based on building materials

Classified by building material, traditional Chinese dwellings can be divided into the following three categories, which are brick structure of the North Central Plains region's residence, wooden structure in Yunnan Pro., southwest China's residence, wooden main body structure inside and brick walls outsourced hybrid structure in Southern Yangtze River region's residence (Cao, 2002, pg.15, para.1, trans. by author). All these materials could be easily found based on the natural conditions, which are also commonly applied in each region to meet the needs of the residents (Zhang, 2002).

Table 2. Building material classification of traditional dwellings

\begin{tabular}{l|l|l}
\hline \multicolumn{1}{c|}{$\begin{array}{c}\text { Building } \\
\text { materials }\end{array}$} & \multicolumn{1}{c}{$\begin{array}{c}\text { Typical } \\
\text { design }\end{array}$} & \multicolumn{1}{c}{$\begin{array}{c}\text { Corresponding } \\
\text { dwellings }\end{array}$} \\
\hline $\begin{array}{l}\text { Brick } \\
\text { structure(B) }\end{array}$ & $\begin{array}{l}\text { Courtyard, } \\
\text { The Earth } \\
\text { Tower, Cave-style } \\
\text { dwellings }\end{array}$ & $\begin{array}{l}\text { Peking quadrangle, } \\
\text { Anhui dwelling, } \\
\text { Fujian dwelling, } \\
\text { Shanxi cave house, } \\
\text { Henan cave house }\end{array}$ \\
\hline $\begin{array}{l}\text { Wooden } \\
\text { structure(W) }\end{array}$ & $\begin{array}{l}\text { Ganlan Wood } \\
\text { building }\end{array}$ & $\begin{array}{l}\text { Western Hunan hanging house } \\
\text { (Diaojiaolou), } \\
\text { Yunnan bamboo house }\end{array}$ \\
\hline $\begin{array}{l}\text { W+B hybrid } \\
\text { structure }\end{array}$ & $\begin{array}{l}\text { Southern Yangtze } \\
\text { River water-town } \\
\text { dwelling }\end{array}$ & $\begin{array}{l}\text { Zhejiang dwelling, } \\
\text { Hangzhou dwelling, } \\
\text { Suzhou dwelling }\end{array}$ \\
\hline
\end{tabular}

Classification based on habitats and life-styles

By the view of living habitat and life-style, traditional Chinese dwellings generally divided into courtyard-style 
dwelling, floor-style dwelling and cave-style dwelling (Zhang, 2002, pg.90, para.4, trans. by author). Courtyardtyle dwelling are usually found in North China, while a large number of cave-style dwellings are in the northwest of China. What is worth mentioning is the floor-style dwelling, which is commonly seen in South China with the buildings of several floors. People could wear shoes and walk ups and downs casually in such houses (Luo, 2008, pg.11, para.3, trans. by author). In all dwelling modes, courtyard-style dwelling is one of China's most popular residential types, and also have the most advanced construction techniques and the most abundant elements.

Table 3. Habitat and life-style classification of traditional dwellings

\begin{tabular}{l|l|l}
\hline $\begin{array}{c}\text { Habitats and } \\
\text { life-styles }\end{array}$ & \multicolumn{1}{c|}{$\begin{array}{c}\text { Typical } \\
\text { design }\end{array}$} & \multicolumn{1}{c}{$\begin{array}{c}\text { Corresponding } \\
\text { dwellings }\end{array}$} \\
\hline Courtyard-style & Courtyard & $\begin{array}{l}\text { Peking quadrangle, } \\
\text { Anhui dwelling }\end{array}$ \\
\hline Floor-style & $\begin{array}{l}\text { Ganlan Wood } \\
\text { b u i l d i n g, } \\
\text { The Earth } \\
\text { Tower }\end{array}$ & $\begin{array}{l}\text { Western Hunan hanging house } \\
\text { (Diaojiaolou), } \\
\text { Yunnan bamboo house, } \\
\text { Fujian dwelling, } \\
\text { Minnan dwelling }\end{array}$ \\
\hline Cave-style & $\begin{array}{l}\text { Cave-s ty le } \\
\text { dwelling }\end{array}$ & $\begin{array}{l}\text { Shanxi cave house, } \\
\text { Henan cave house }\end{array}$ \\
\hline
\end{tabular}

\subsection{Introduction on Seven Typical Traditional Chinese Dwellings}

To give a dialectical overall view on Chinese traditional dwellings, 7 types of dwellings are chosen for comparison. Each of them represents for a kind of typical residence design that is commonly included in China now. There are $70 \%$ Chinese living in these 7 traditional vernaculars or other modernized types of them and each of them contains a strong local characteristics that absorb from local cultures. According to different areas, they are called Southern Yangtze River dwelling, Anhui local-style dwelling, Peking dwelling, Northwest dwelling, Southeast dwelling, Western Hunan dwelling and Inner Mongolia dwelling.

\section{Southern Yangtze River dwelling}

Due to geographical advantages, the area in the south of Yangtze River Delta is rich in water resource, so most towns and cities are built along the banks, forming a long bustling street. Zhouzhuang Village is a typical one of them. Since most houses are built along the river, folks tile big building stones at the bottom of walls to proof water or humidity (Shan, 2003, pg.16, para.2, trans. by author). Besides, the dwellings in this area adopts the plane layout pattern, which is more or less like the Peking dwelling. The number of the rooms is usually odd number due to the culture reasons. Grilles are usually built on the walls for ventilation, together with the windows in both front doors and back doors. The dwellings are built according to topography, which present the reasonable use of space, layout flexibility, construction aesthetics, materials and so on and give the fresh and lively appearance. The distribution structure usually contains courtyard door, hospital lobby, residential and other typical characteristics of the courtyard with elements like gingerbread, roses, bats and several other images to symbolize the happiness and traditions of Chinese culture.
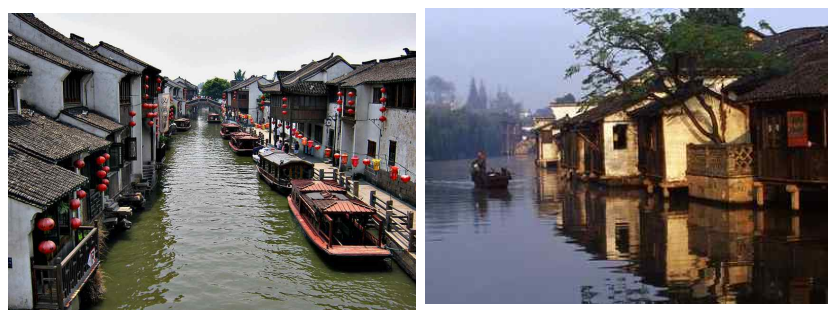

Fig. 1. Southern Yangtze River dwelling (Website: http://image.baidu.com)

Anhui local-style dwelling

Anhui local-style dwelling house has a special historic culture and geographic circumstance, millions or former residences from Ming and Qing dynasties have been well-preserved in southern areas of Anhui Province. Southern Anhui has many well preserved memorial archways enjoying equal reputation with its ancient shrines and folk houses (Shan, 2003, pg.17, para.1, trans. by author). Also the dwellings in Ancient Villages in Southern Anhui, Xidi and Hongcun Village is famous for their water gate - channels - the Moon Pond - the South Lake, together with the small pond at every yard, compose an integrated water system and become the spirit of the local style. According to the characteristics of the local climate and topography, Anhui traditional residential buildings are mostly two-story buildings of various shapes, which give the delicate and simple experience.
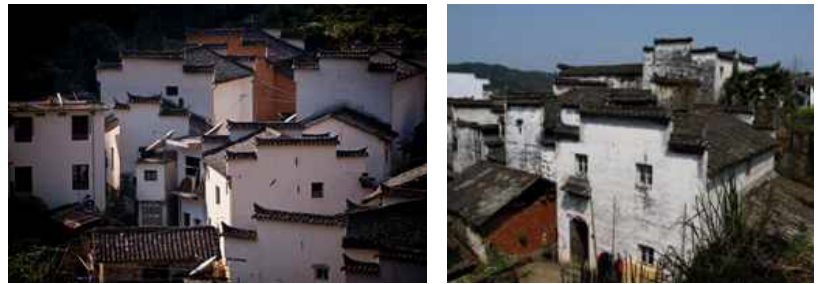

Fig. 2. Anhui Local-style dwelling(http://image.baidu.com) 


\section{Peking dwelling}

Peking dwelling, which is also called Peking courtyard is the most well-known traditional vernacular dwelling among all the patterns. It is also the one that with the maturest structure technology and most advanced material. The distribution structure of quadrangle usually contains courtyard door, hospital lobby, residential and other typical characteristics of the courtyard with elements like gingerbread, roses, bats and several other images to symbolize the happiness and traditions of Chinese culture. The construction of Peking house also acts in accordance with fengshui, which is generally regarded as the representative of Chinese traditional architecture.
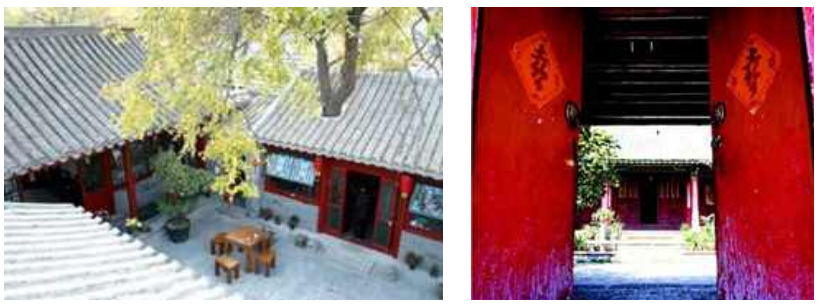

Fig. 3. Peking dwelling(http://image.baidu.com)

\section{Northwest dwelling}

Northwest dwelling, which is also called the Cavestyle dwelling has several explicitly regional characteristics in the natural ecology that remaining the most primitive architectural features among all of the vernacular dwelling patterns. The drought area in the Loess plateau placed in the northwest China is the area where this kind of dwellings most centralized (Zou, 2005, pg.8, para.6, trans. by author). The most obvious feature of Cave-style dwelling is that the shape of dwelling is quite natural and free, the whole settlement scattered loosely, which is believed to form in the long time of earthquake, encountering typhoon and other frequent disasters. The materials of the houses, which used to be stones, soil, weeds and grasses, were easy to find in the local. Nowadays, more and more people still use the engineering structure or the brick structure. To summarize, due to the restrictions of the local environment, the northwest dwellings are the deputy of simple and of practical use with most residents use their houses as the production places. And the brick heat bed is also welcomed in northwest dwellings.
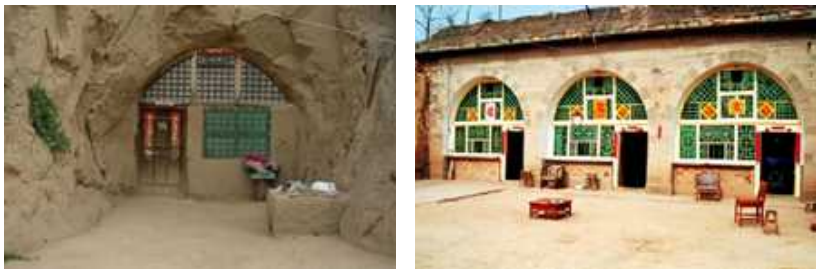

Fig. 4. Northwest dwelling(http://image.baidu.com)

\section{Southeast dwelling}

The Earth Tower is the typical representative of Southeast dwellings. It was constructed using fire-resistive material so that practically impregnable. The Earth Tower is quite spacious and made up of different shapes like square, semi-circular, rectangular and round. The round ones are most common. Most of them are three stories high with a diameter of 70-80 meters. It is called a "group-oriented" residence, which usually with one main entrance. Inside the entrance is a huge central courtyard where all the doors of the rooms and inner windows open facing it (Wang, 2002, pg.158, para.2, trans. by author). Normally, the rooms at the ground level, except the hall and the staircases, are used as kitchens and dining rooms (Zhou, 2011, pg.7, para.4, trans. by author). It is the representative of group living culture, which are commonly found in the southeast villages.
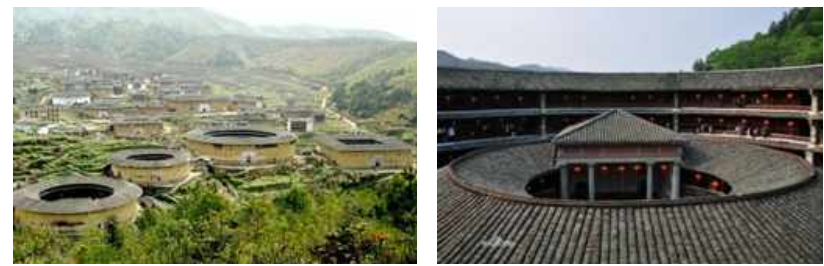

Fig. 5. Southeast dwelling(http://image.baidu.com)

\section{Western Hunan dwelling}

Western Hunan has many Ganlan wood buildings. Diaojiaolou is a kind of them, which is the typical pattern among Western Hunan dwelling that distributes mostly in the mountains of minority nationalities areas. Such a style has pushed the space form and space combination of storied dwelling, the support, suspension and stagger floor along the hills, the techniques of mortise and tenon to a very high level (Sha, 2000, pg.9, para.1, trans. by author). It also demonstrates rich material and spiritual civilizations in combination with the unique national and folk cultures of the minority nationalities. The house is built on the ground, connecting to the main house with three sides held by pillars. Diaojiaolou has many benefits, especially in avoiding poisonous snakes and wild animals to break into the house. Built on distinctive ethnic characteristics, Diaojiaolou is regarded as than the e "living fossil" of Bachu Culture.

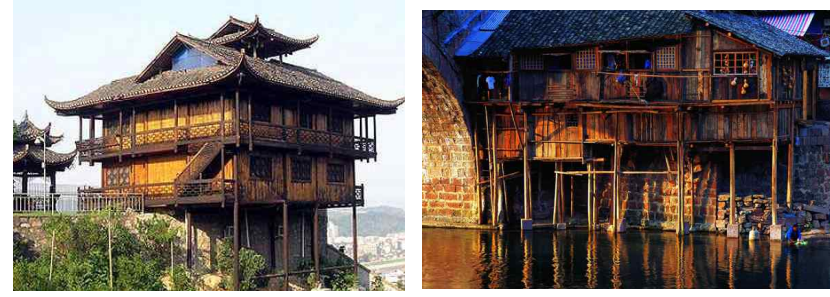

Fig. 6. Western Hunan dwelling(http://image.baidu.com) 
Inner Mongolia dwelling

Extensive prairie is a big stage for the Mongol nationality to ride or fight alien races on horses, and for nomads, the best dwelling is Mongolian yurt (Zhang, 2002, pg.92, para.1, trans. by author).

Mongolian yurt is easy to build, to move, to make and to demount. It can resist the cold and is convenient for herding. The nomads create this kind of dwelling to adapt the nomadic life and nomadic production. Mongolian yurt can date back to Huns, over 2000 years ago ${ }^{3)}$. This typical dismountable dwelling used in northern China has been used ever since.
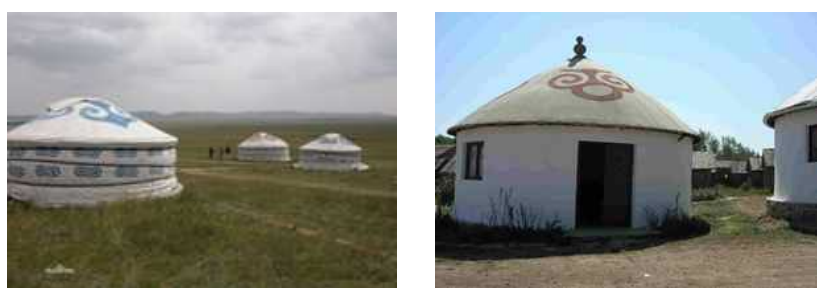

Fig. 7. Inner Mongolia dwelling(http://image.baidu.com)

\section{Research Methodology}

In this section, features of seven typical Chinese traditional dwellings in different areas will be compared by historical, geographical, structural and tinctorial aspects to see the direct regular and indirect regular between them. The reason of selecting these four features is that they are easily affected by regionality and culture thus reflect the differences. Each of the comparative elements has a evaluation scale to reflect their degrees.

\subsection{From Time Sequence and Historical Length Perspective}

The originality of Southern Yangtze River dwelling can be traced back to Chinese Hemudu Culture that began 7000 years ago. Then officialdoms started to live in this area from Han Dynasty4). Because of war, more and more people migrated from north to south to make a living (Zou, 2005, pg.8, para.2, trans. by author). It was the first impression of traditional Chinese vernacular in history.

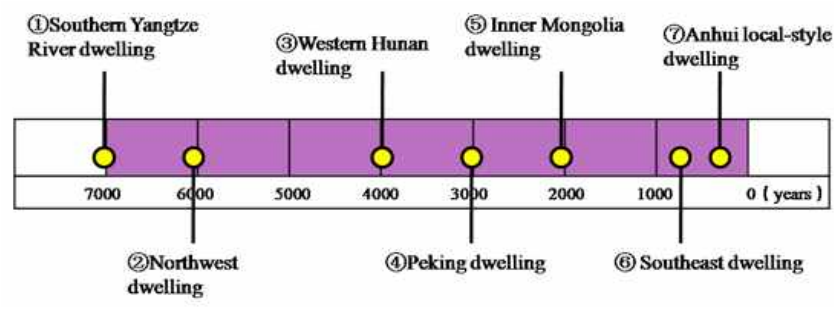

Fig. 8. Comparison of time sequence \& historical length

3) http://baike.baidu.com/view/24592.htm, 20130927.

4) http://baike.baidu.com/view/392303.htm, 20130927.
As can be seen in figure 8, 7 types of traditional Chinese dwellings are ordered by their historical length from 7000 to 0 years. The scale is divided into 7 equivalent parts and every interval stands for one thousand years. The yellow spots show the years that traditional dwellings appear.

The oldest one is South Yangtze River dwelling that with its over 7000 years' long historical standing. The second one is Northwest dwelling appeared at Chinese Yangshao culture of 6000 years ago. Western Hunan dwelling is the third one that began at Primeval times of over 4000 years ago. Peking dwelling began at Western Zhou Dynasty of more than 3000 years ago took over the forth position, and Inner Mongolia dwelling that began at Chinese Xiongnu period of more than 2000 years ago was the fifth. The comparatively present ones were Southeast dwelling of more than 800 years' history began at Song and Yuan Dynasties, Anhui local- style dwelling of 490 years' history began at Ming and Qing Dynasty.

\subsection{From Geographical Distribution Perspective}

The geographical distributions of 7 traditional dwellings are marked with colors in the map of China(Figure 9). Though it is difficult to define the clear boundaries, the center places and the rough scope are easily understood.

As shown in figure 10, 7 types of traditional Chinese dwelling are ordered by their geographical distribution from $50^{\circ}$ to $20^{\circ}$ north latitude $(\mathrm{N})$. The scale is divided into 6 equivalent parts and every interval represents $5^{\circ} \mathrm{N}$. The yellow spots show degrees of north latitude where traditional dwellings located in.

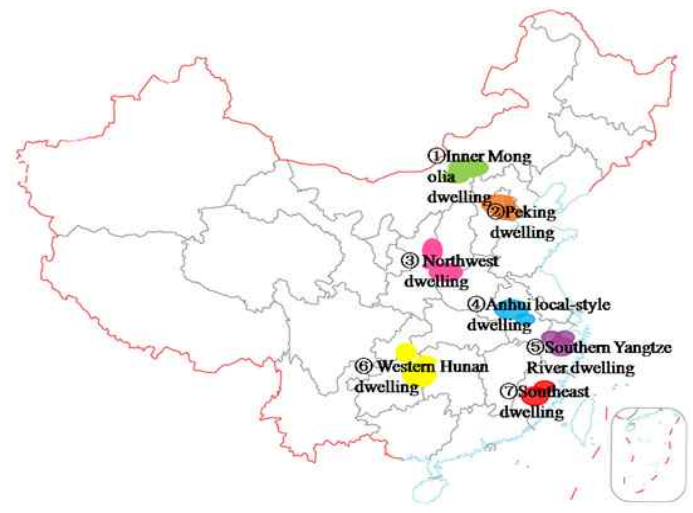

Fig. 9. Distributions of 7 dwellings in the map of China

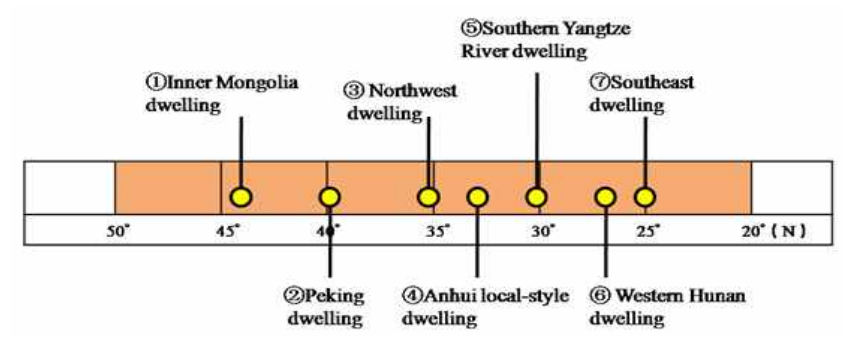

Fig. 10. Comparison of geographical distribution 
Inner Mongolia dwelling is the northest one among 7 patterns. It is mainly located at Inner Mongolia nomadic areas that in the middle part of Inner Mongolia Pro., closing to $43^{\circ} \mathrm{N}$. The next is Peking dwelling mainly distributes in Peking and Northern China close to $40^{\circ} \mathrm{N}$. Northwest dwelling is the third one that located at northwest China in the Loess plateau area close to $35.5^{\circ} \mathrm{N}$. Anhui local-style dwelling, which mainly seen in southern Anhui Pro. closing to $33^{\circ} \mathrm{N}$. is the forth one. Southern Yangtze River dwelling is the next that many seen in median Zhejiang and Jiangsu Pro., close to $30^{\circ} \mathrm{N}$. The sixth is Western Hunan dwelling that mainly distributes in western Hunan, eastern Guizhou and southeast Chongqing municipality, near to $26.5^{\circ} \mathrm{N}$. Southeast dwelling that mainly appears in southwest Fujian province, closing to $25^{\circ} \mathrm{N}$ is considered as the most southerly one.

\subsection{From Structural Material Perspective}

In this comparison the Rockwell Scale was used to evaluate the hardness of the structural materials of 7 traditional dwellings. The Rockwell Scale is a hardness scale based on indentation hardness of a material. It can be used to determine the hardness by measuring the depth of penetration of an indenter under a large load compared to the penetration made by a preload5).

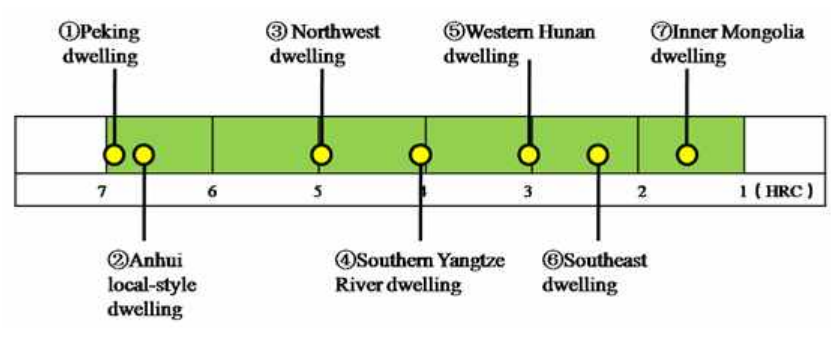

Fig. 11. Comparison of structural material

As can be seen in figure 11,7 types of traditional Chinese dwelling are ordered by their structural material from $7 \mathrm{HRC}$ to $1 \mathrm{HRC}$. The scale is divided into 6 equivalent parts and every interval represents $1 \mathrm{HRC}$. The yellow spots show the degrees of their hardness.

Peking dwelling and Anhui local-style dwelling that are mainly made up of stiff brick and stone $(\mathrm{HRC} \approx 7)$ occupied the first and the second hardest positions. The post and panel(HRC $\approx 6.5$ ) of Anhui local-style dwelling softened its hardness up. Next ordered as Northwest dwelling is made up of loess $(\mathrm{HRC} \approx 5)$, South Yangtze River dwelling is made up of brick and wood mixed(HRC $\approx 4$ ), Western Hunan dwelling is made up of wood and

5) http://en.wikipedia.org/wiki/Rockwell_scale, 20130930. nasonry $(\mathrm{HRC} \approx 3)$, Southeast dwelling is made up of immature soil( $\mathrm{HRC} \approx 2.9$ ), silver sand $(\mathrm{HRC} \approx 2.4$ ), lime(HRC $\approx 2$ ), and, Inner Mongolia dwelling is mainly made up of willow $(\mathrm{HRC} \approx 2)$ and felt $-\operatorname{cloth}(\mathrm{HRC} \approx 1)$.

\subsection{From Exterior Color and Style Perspective}

The Practical Color Coordinate System(PCCS) is used to measure saturations of every dwelling. PCCS is a discrete color space indexed by hue and tone. It is developed by the Japan Color Research Institute(Yin, 2002, pg.52, para.9, trans. by author). PCCS divides saturation into 10 level from 0 to 9 , defined black, white and grey infinitely closing to 0 level, other colors' levels gradually adding up following their brightness.

As shown in figure 12, 7 types of traditional Chinese dwelling are ordered by their exterior color from 0 to 9level. The scale is divided into 9 equivalent parts and every interval represents 1 level. The yellow points show levels of each exterior color.

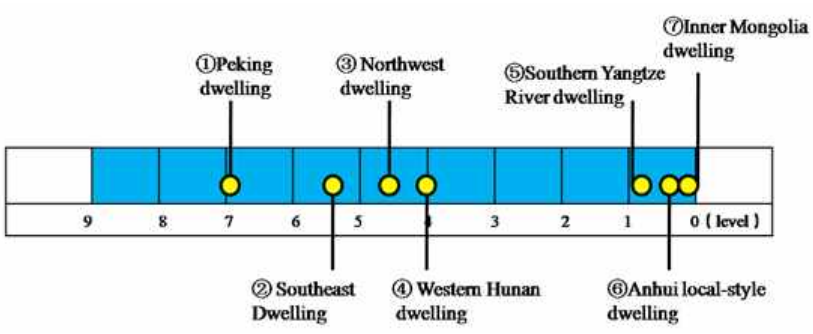

Fig. 12. Comparison of exterior color\&style

Peking dwelling, which has three different colors mixed, especially the bright-coloured vermilion (level 7) makes it look brighter and more vivid. was considered as the most colorful one among all patterns. Next ordered as Southeast dwelling with ashen (level 5) and brown (level 6) surface, ochreous (level 5) Northwest dwelling, wooden color and biscuit (level 4) Western Hunan dwelling. Southern Yangtze River dwelling, Anhui local-style dwelling and Inner Mongolia dwelling were considered as dark ones for their white exterior color (level 0).

For an additional remark, from construction aesthetics and culture perspective, different cultures have cultivated and brought out different dwelling styles. According to the seven dwellings mentioned above, aesthetics could be found in each form of dwelling. First of all, the beauty of mind is reflected in the dwellings, with Chinese traditional doctrines of "respect for nature" and "follow the nature" as the essential merits. Just as some classical Chinese novels have depicted. Furthermore, the beauty of dwelling are reflected in the appearance, such as in 
the aspects of environment, settlement, style, courtyard, structure, materials, decorations, thralls and furnishing. For example, the dwelling in Yangtze River illustrates the beauty of silence and grace, the Peking house represents dignity and tradition, Mongolian swelling is with minority features and unique thinking, while the dwellings in South China shows the art and classical beauty. Though the basic ideology acting in accordance with the traditional doctrines are more or less the same, different cultures have also influenced the dwelling styles.

\section{Results of the Research on 7 Traditional Dwellings}

China's varied topography and centuries-old history gave birth to more than 40 kinds of traditional vernacular dwellings, every kind of them has an ancient and mysterious culture (Wang, 2002, pg.165, para.7, trans. by author). Out of the culture of each traditional dwelling, a phoenix of development can arise. 7 typical types of them have been chosen for analysis. They are Southern Yangtze River dwelling, Anhui local-style dwelling, Peking dwelling, Northwest dwelling, Southeast dwelling, Western Hunan dwelling and Inner Mongolia dwelling. At the same time 4 kinds of factors have been chosen as estimate standards. They are the length of historical period, the position of geographical distribution, the hardness of structural material and the saturation of exterior color. All of them are ordered from the first to the seventh according to different standards. By connecting every spot of each dwelling using a line, the specific results are shown in the figure below.

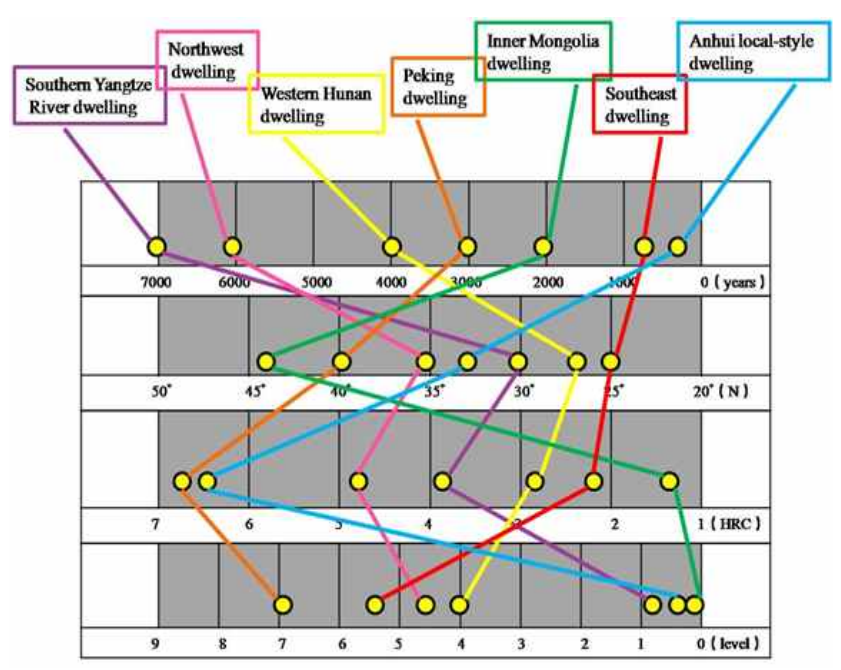

Fig. 13. The line chart of overall comparison

Firstly, historical length in a certain extent reflects the differences between dwellings in different geographical distributions. It is related with China's economic development in the progressive geographical characteristics. The originality of Southern Yangtze River dwelling can be traced back to Chinese Hemudu Culture when ancestors began to live in this area for its advantageous natural resources and convenient transportation (Lu. \& Li., 2008, pg.7, para.8, trans. by author). Northwest dwelling, distributed in Central Plains region where as the culture center of ancient China was also in a rapid expansion. With the development of economic from eastern to the central and the north-moving of culture, a large number of residential types boarded on the stage of history. Western Hunan dwelling, Peking dwelling, Inner Mongolia dwelling, Southeast dwelling and Anhui local-style dwelling appeared one after the other.

Secondly, there are more regular type dwellings in the north while much more irregular ones in the south. Seeing from the aspect of cultural character, northerners are focused more on the relative cultural norms than southerners. People in north with their rigorous attitude have paid more attention to realistic practice. They believe in calm and down-to-earth attitude towards life, advocating the ethical norms. From the physical aspect, it is relatively cold in the north, while the ancient north has been a vast territory with a sparse population, on which, they built broader courtyard to get more sunlight. Therefore it is no wonder of the appearance of the orderly living space like Peking dwelling, Inner Mongolia dwelling and Anhui local-style dwelling. On the contrary, observing the case of Western Hunan dwelling and Southern Yangtze River dwelling, the attitude of southerners are more lively and fickle with free living space. On the other hand, it is relatively warmer in the south, people should consider more landform than weather because of the complex terrain geography, especially in the hilly areas, and dwellings had to follow the local conditions.

Thirdly, in order to defense dust storms and the northern enemy's invasion, dwellings in north are more common in wall-type (Huo, 1989, pg.97, para.4, trans. by author) that mainly be constructed with stiff stone and earth, while for adapting to the rainy humid climate, and make full use of the rich in timber resources, southern dwellings are more common in roof-type (Huo, 1989, pg.101, para.6, trans. by author) that mainly be constructed with wood and brick mixed. The typical character of wall-type is similar with courtyards, it forms a shape of "口" means security and stability that the northerners need the hardness of stone and earth to insure their physical sense of safety. Peking dwelling and Anhui local-style dwelling are typical ones stand for this type. Northwest dwelling that mainly made up of 
loess is an exception in north, for its special structural material without brick that restricted by the terrain. Even though the hardness of loess is smaller than brick, it is much harder than materials common used in south, such as wood immature soil and silver sand. Likewise, Inner Mongolia dwelling in order to easy for the Mongol nationality to build and move, has much influenced by ethnic culture so that relatively belong with roof-type that made up of softer materials.

Fourthly, in view of the exterior color, dwellings in the south are many in simple and natural colors while northern dwellings are common seen in magnificent and bright colors. This is because people in areas like Western Hunan or Southern Yangtze River are simple and honest, they'd like to keep a low profile attitude to life (Sha, 2000 , pg.12, para.2, trans. by author). Nevertheless, the northern part is comparatively common seen in brighter colors like Peking dwelling and Northwest dwelling, for the northerners are prefer being outstanding. They'd like to manifest their superiority through the light of bright colors. As the areas where the capital of a country located in, Peking dwelling showed its royal dignity by bright-colored vermilion, which stands for respect, allegiance, and deep impression.

Fifthly, Inner Mongolia dwelling belongs to northern part in geographical distribution but has the softest material and lowest saturation, Southeast dwelling located in southern part at the same time occupied the seconde position of order in the scale of exterior color, both of them are exceptions and also showed a result of culture integration between north and south.

The last but not the least, the aesthetics of the architecture are reflected in different dwellings. And dwellings are founded on the roots of the culture, based on which they also show the characteristics of the national identity(Shan, 2003, pg.17, para.5, trans. by author). And the traditional dwelling also carries the signals and times characters, such as Diaojiaolou, which is invented to protect residents from wild animals and natural disasters by the traditional Chinese wisdom. What's more, dwelling culture in the other countries are not as diversified as in China due to the large territory from the north to nearly the equatorial. The geography location gives rise to the multi-forms of dwellings, which consisted of the abundant Chinese culture. And different kinds of beauty also emerged due to the diversification in different cultures.

\section{Conclusion}

In general, by classifying traditional Chinese dwellings from modeling shape, building material, habitat and life-style points of view, they are divided into several types. From the shape point of view, they are divided into regular type and irregular type. Because the traditional Chinese have emphasis on the shape, while being regular is with the good meanings. The irregulartype of dwellings are reducing year by year with the development of modern technology, with which many building barriers could be overcome. Classified by building material, traditional Chinese dwellings can be divided into brick structure, wooden structure, wooden and brick hybrid structure. Comparatively speaking, brick structure is the most endurable due to its solidness, while the wooden structure is likely to be damaged by the natural disasters. By the view of living habitat and life-style, traditional Chinese dwellings generally divided into courtyard-style dwelling, floor-style dwelling and cavestyle dwelling.

To give a dialectical overall view, 7 types of dwellings were chose for comparison. Each of them represents for a kind of typical residential design that almost included comparatively common ones in China now. By comparing features of these 7 typical traditional Chinese dwellings in different areas from historical, geographical, structural and tinctorial aspects, historical length showed a certain extent affect on the differences between dwellings in different geographical distributions that related with China's economic development. Distribution also influenced the shape into more regular or more irregular. There are more wall-type that mainly be constructed with stone and earth in the north while more roof-type in the south to adapt to its rainy humid climate. Dwellings in the south are many in simple and natural colors while northern dwellings are common seen in magnificent and bright colors. The results showed that it's not only natural terrain but also cultural mentality effected on the changes of regionality. The excluded cases like Inner Mongolia dwelling and southeast dwelling showed the culture integration between dwellings.

Thus, protecting on traditional dwellings is of great necessities and this study will bring benefits mainly in four aspects. To begin with, the research on Chinese traditional dwellings is the important link in the protection of traditional dwellings, in which the culture, characteristics of the times of different regions can be reflected. The nation does not want to see the traditional dwellings are reduced to the views for the tourists. Besides, the aesthetics of traditional dwellings is a necessary complement and reference to the construction schools all over the world. Furthermore, the aesthetics of traditional dwellings is a complicated system based on various subjects, such 
as the studies of Chinese civilization, aesthetics subject, construction science and so on, which contains the philosophy of Chinese traditional wisdom and is well worth in-depth exploration. The last but not the least, the research on traditional dwellings not only brings opportunities to promote Chinese wisdom on dwellings and residential culture, but also a way to arouse the attention related government branches and institutions, or even the international society to take protection actions on the traditional culture.

\section{Acknowledgements}

This work was supported by the National Research Foundation of Korea(NRF) grant funded by the Korea government(MSIP)(No. 2008-0061908)

\section{References}

[1] Fletcher, B. Cruickshank, D,Sir Banister Fletcher's a History of Architecture. Architectural Press, 1996, p. 109-110.

[2] Schinz, A. The Magic Square: cities in ancient China, Edition AxelMenges, 1996, p. 427-428.

[3] Steinhardt, N. S. "The Tang Architectural Icon and the Politics of Chinese Architectural History," The Art Bulletin, 2004, 86(2), p. 228-254

[4] Weston, R. \& Blondal. Utzon : inspiration, vision, architecture.. 2002, p. 9-12

[5] Cao, W. Residential Culture between China and Japan: Comparison on Traditional Housing between China and Japan. Tongji University Press, 2002, p. 12-17.

[6] Gao, L. T. Ancient Architecture in the Quantification of Color. Traditional Chinese Architecture and Gardens, 1998, 4, p. 49-50.

[7] Gu, D. N., Zhou, J. Sh. Geographical Distribution and Evolution Pattern of Chinese Traditional Local-style Dwelling Houses. Economic Geography, 2010, 30(3), p. 108-133.

[8] Huo, Y. Z. Beijing Natural Geography. Beijing Normal University Press, 1989, p. 95-140.

[9] Jiang, X. Zh. Culture Inheritance of Architecture Group Space. Southwest Jiaotong University, 2005, p. 19.

[10] Liang, W. G. How to Classify Chinese Traditional Housing. Wuhan University of Technology, 2004, p. 2-3.

[11] Liu, D. Z. Introduction to Chinese Residence. Baihua Literature \& Art Press, 2003, p. 29-38.

[12] Lu, F., Li, J. Overall Interpretation of Contemporary Architectural Regionality. Urban Architecture, 2008, 6(4), p. 7-8.

[13] Luo, W. Research on Hunan Pro. Wang City Jinggang Historic Town. Wuhan University of Technology, 2008, p. 5-15.

[14] Sha, R. Natural Geographic Background of Chinese Traditional Dwelling Architecture Culture. Geographic Science, 2000, p. 9-15.

[15] Shan, D. Q. Chinese Vernacular Dwelling. China Intercontinental Press, 2003, p. 3-17.

[16] Wang, Q. J. Chinese Folk Residential Construction. China Machine Press, 2002, p. 158-169.

[17] Wang, S. Regionality of Architectural Culture. Anhui Architecture,
2006, 39(2), p. 22-23.

[18] Wang, Z. F. Chinese Architecture Art Outline. Shanxi Education Press, 2001, p. 277-290.

[19] Yang, L., Qiu, J. Culture Regeneration of Architectural Space and Organic Inheritance of Urban Context. Urban Architecture, 2007, 21(8), p. 18-19.

[20] Yin, S. J. Urban Color Landscape Planning\&Design Research. Tsinghua University, 2002, p. 49-54.

[21] Zou, Y. H. Discussion on "Construction Words" in the Development of Chinese Contemporary Architecture. Tianjin University, 2005, p. 8-9.

[22] Zhang, L. Function, Form and Structure of Architecture and Architectural Creation. Inner Mongolia Science\&Technology and Economy, 2002, 15(2), p. 89-93.

[23] Zhao, K. A Comparative Study of Traditional Courtyard Space. Northeast Forest University Press, 2006, p. 11-12.

[24] Zhong, X. P., Zhang, M. L. Air Courtyard--A New Thinking that adopted Spirit of Chinese Traditional Local-style Dwelling. Huangzhong Architecture, 2006, 10(1), p. 36-37.

Received October 31, 2013;

Final revision received January 13, 2014;

Accepted January 17, 2014; 